\title{
Diagnostic Accuracy of Transthoracic Echocardiography to Predict Fluid Responsiveness by Passive Leg Raising in the Critically Ill: A Meta-Analysis
}

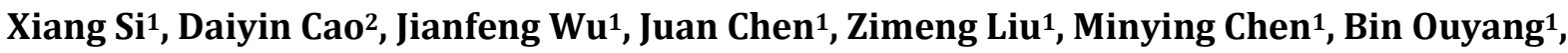 \\ Xiangdong Guan ${ }^{1}$ \\ ${ }^{1}$ Department of Surgical Intensive Care Unit, The First Affiliated Hospital of Sun Yat-sen University, Guangzhou, China \\ ${ }^{2}$ Department of Critical Care Medicine, The Sixth Affiliated Hospital of Sun Yat-sen University, Guangzhou, China \\ Email: guanxiangdong1962@163.com
}

How to cite this paper: Si, X., Cao, D.Y., Wu, J.F., Chen, J., Liu, Z.M., Chen, M.Y., Ouyang, B. and Guan, X.D. (2016) Diagnostic Accuracy of Transthoracic Echocardiography to Predict Fluid Responsiveness by Passive Leg Raising in the Critically Ill: A Meta-Analysis. Open Journal of Emergency Medicine, 4, 83-92.

http://dx.doi.org/10.4236/ojem.2016.44011

Received: October 11, 2016

Accepted: November 5, 2016

Published: November 8, 2016

Copyright (c) 2016 by authors and Scientific Research Publishing Inc. This work is licensed under the Creative Commons Attribution International License (CC BY 4.0).

http://creativecommons.org/licenses/by/4.0/ (c) (i) Open Access

\section{Abstract}

Background: Hemodynamic instability is common in critical patients and not all patients respond to fluid challenge, so we need accurate and rapid hemodynamic techniques to help the clinicians to guide fluid treatment. Numerous hemodynamic techniques have been used to predict fluid responsiveness till now. Transthoracic echocardiography (TTE) appears to have the ability to predict fluid responsiveness, but there is no consensus on whether it can be used by passive leg raising (PLR). Methods: We performed a literature search using MEDLINE (source PubMed, from 1947), EMBASE (from 1974) and the Cochrane Database of Systematic Reviews for prospective studies with no restrictions. Pooled effect estimates were obtained by using random-effects meta-analysis. Results: 7 prospective studies involving 261 patients and 285 boluses were identified. The pooled sensitivity and specificity of TTE are $86 \%(79 \%-91 \%)$ and $90 \%(83 \%$ - 94\%), respectively. The summary receiver operating characteristic (sROC) curve shows an optimum joint sensitivity and specificity of 0.88 , with area under the sROC curve (AUC) of 0.94 . The result of diagnostic odds ratio (DOR) is 50.62 (95\% confidence interval [CI]: $23.70-108.12)$. The results of positive likelihood ratio (+LR) and negative likelihood ratio (-LR) are 7.07 (95\% CI: 4.39 - 11.38) and 0.19 (95\% CI: 0.13 - 0.28), which indicated strong diagnostic evidence. Conclusions: TTE is a repeatable and reliable noninvasive tool to predict fluid responsiveness in the critically ill during PLR with good test performance. This meta-analysis brings evidence to employ well-trained clinician-echocardiographers to assess patients' volume statue via TTE to benefit daily work in intensive care units (ICUs). 


\section{Keywords}

TTE, PLR, Fluid Responsiveness, Meta-Analysis

\section{Introduction}

The management of the critically ill patient to optimization the tissue oxygen delivery is an essential part in intensive care unit (ICU). Insufficient intravascular loading in the early resuscitation of acute sepsis results in tissue under perfusion, organ dysfunction, and acidosis. Excessive fluid administration has also been shown to be detrimental in the perioperative setting and in acute lung injury, prolonging both time on mechanical ventilation and time in intensive care [1] [2]. However, it has been reported 50 percent of patients do not exhibit the desired effect after fluid bolus [3] and more than half of patients have the risk of excessive fluid administration [4]. It is therefore essential to have reliable tools for predicting the efficacy of volume expansion (VE) and thus distinguishing patients who might benefit from VE from those in whom the treatment is likely to be inefficacious.

For the past 10 years, many studies have focused on the prediction of fluid responsiveness. Static hemodynamic indices (such as central venous pressure [CVP] or pulmonary artery occlution pressure $[\mathrm{PAOP}]$ ) are demonstrated to be little value in predicting fluid responsiveness [5] [6]. Dynamic indices (such as stroke volume variation [SVV] or pulse pressure variation [PPV]), based on analysis of preload dependence, have been validated to predict fluid responsiveness [5] [7] [8] [9]. And now modern intensive care is increasingly concerned with the avoidance of unnecessary invasive procedures which contribute to patient morbidity either directly or more often through the associated risk of catheter-related bloodstream infection [10]. So, invasive or miniinvasive methods are replacing by new methods focused on non-invasive.

Passive leg raising (PLR) is a reversible maneuver that mimics VE by shifting venous blood from the lower limbs toward the intrathoracic compartment [11]. This provides a transient volume load of between 150 and 300 milliliters to the central circulation in one minute [12] [13]. Because the heart (left and right ventricles) works on the stiff portion of the Frank-Starling relationship, therefore PLR can increase cardiac preload as "auto-transfused" into the central circulation [11]. Transthoracic echocardiography (TTE) is increasingly used for noninvasive hemodynamic assessment of critically ill patients since high-quality images and Doppler signals are obtained with recent TTE equipment [14]. TTE provides clinicians with valuable information including stroke volume, left ventricular preload, and filling. The stroke volume can be easily obtained using the left ventricular outflow track Doppler method [21]. But there is no consensus on whether it is useful during passive leg raising. Accordingly, the aim of this study is to answer the question: Can transthoracic echocardiography to be used as a tool for predicting volume responsiveness in critically ill by PLR? 


\section{Methods}

\subsection{Study Selection}

Two authors independently performed a search in MEDLINE (using PubMed as the search engine, from 1947), EMBASE (from 1974) and the Cochrane Database of Systematic Reviews for prospective studies with the following key words: ((transthoracic OR thoracic) AND (echocardiograph* OR echog* OR doppler)) AND "passive leg raising".

Only full-text articles in indexed journals were included. Reviews, chapter, case reports, reference network and studies published in abstract form were excluded. No language restriction was imposed. We included only studies with adult patients admitted in ICU. Articles were collected by one reviewer and crosschecked by another reviewer and references of included papers were examined to identify other studies of interest.

\subsection{Inclusion Criteria}

We included full-text studies with the following criteria: 1) PLR was performed and followed with VE; 2) the number of patients and boluses had been counted; 3) the reference standard of predicting fluid responsiveness had been described; 4) sensitivity, specificity and the threshold of the index in identifying those patients who subsequently responded to VE had been calculated.

\subsection{Data Extraction and Quality Assessment}

Data extraction of all variables and outcomes of interest was performed independently by 2 authors independently. For all included studies, two authors extracted the following information by using a standardized form: authors, year of publication, study setting, population, age of patients, number of patients included, ventilation mode, cardiac rhythm (sinus vs. arrhythmias), type and amount of VE, time of VE, definition of responders, position, manufacturer of TTE, amount of VE administered, number and percentage of responders, sensitivity, specificity, best threshold and area under the ROC curve (AUC). Data reporting conformed to the Standards for Reporting of Diagnostic Accuracy (STARD) [15].

We use QUADAS-2 (quality assessment of diagnostic accuracy-2) [16] to assess the quality of included studies on diagnostic accuracy in systematic reviews. The checklist was structured with 4 parts: Patient selection, index test, reference standard and flow and timing.

\subsection{Statistical Analysis}

We used RevMan 5.2 (Cochrane Collaboration, Oxford, UK) to make the QUADAS-2 scale to assess quality of studies on diagnostic accuracy to be included in systematic reviews [17]. Using MetaDiSC 1.4 (Unit of Clinical Biostatistics team of the Ramon y Cajal Hospital, Madrid, Spain), we calculated pooled values of sensitivity, specificity, diagnostic odds ratio (DOR) and area under summary receiver operating characteristic 
(sROC) curve with P-values of less than 0.05 considered statistically significant [18]. Pubilication bias was performed by STATA statistical software 12.0 (StataCorp, College Station, TX) [19].

\section{Results}

\subsection{Article Search}

The initial search yielded 345 articles, of which 93 articles were excluded for not directly concerning of this item. 122 articles were subsequently excluded for review, reference work and book. Based on the inclusion criteria, 65 articles were excluded. 58 articles were subsequently excluded for not using TTE. Finally, 7 full-text articles were included for meta-analysis [20]-[26].

\subsection{Quality of Reporting and Study Characteristics}

Characteristics of the 7 included articles are summarized in Table 1 and the main results are reported in Table 2. The results of QUADAS-2 are showed in Figure 1.

All the included 7 studies (261 patients, 285 boluses) were prospective studies with critically ill patients in shock. 3 studies [21] [23] [24] enrolled patients with spontaneous breathing and in sinus rhythm. The others enrolled patients adapted to ventilator and in rhythm or arrhythmia. 2 studies [22] [26] took transthoracic Doppler ultrasound device $\left(\mathrm{USCOM}^{\circledR}\right)$ for hemodynamic monitoring and traditional transthoracic echocardiography was used by the other studies. In all, 261 patients (range 17 - 89 for single paper) enrolled. A total of 285 fluid boluses were administered. The mean responder rate was $53.9 \%$.

Table 1. Characteristics of studies included in this meta-analysis.

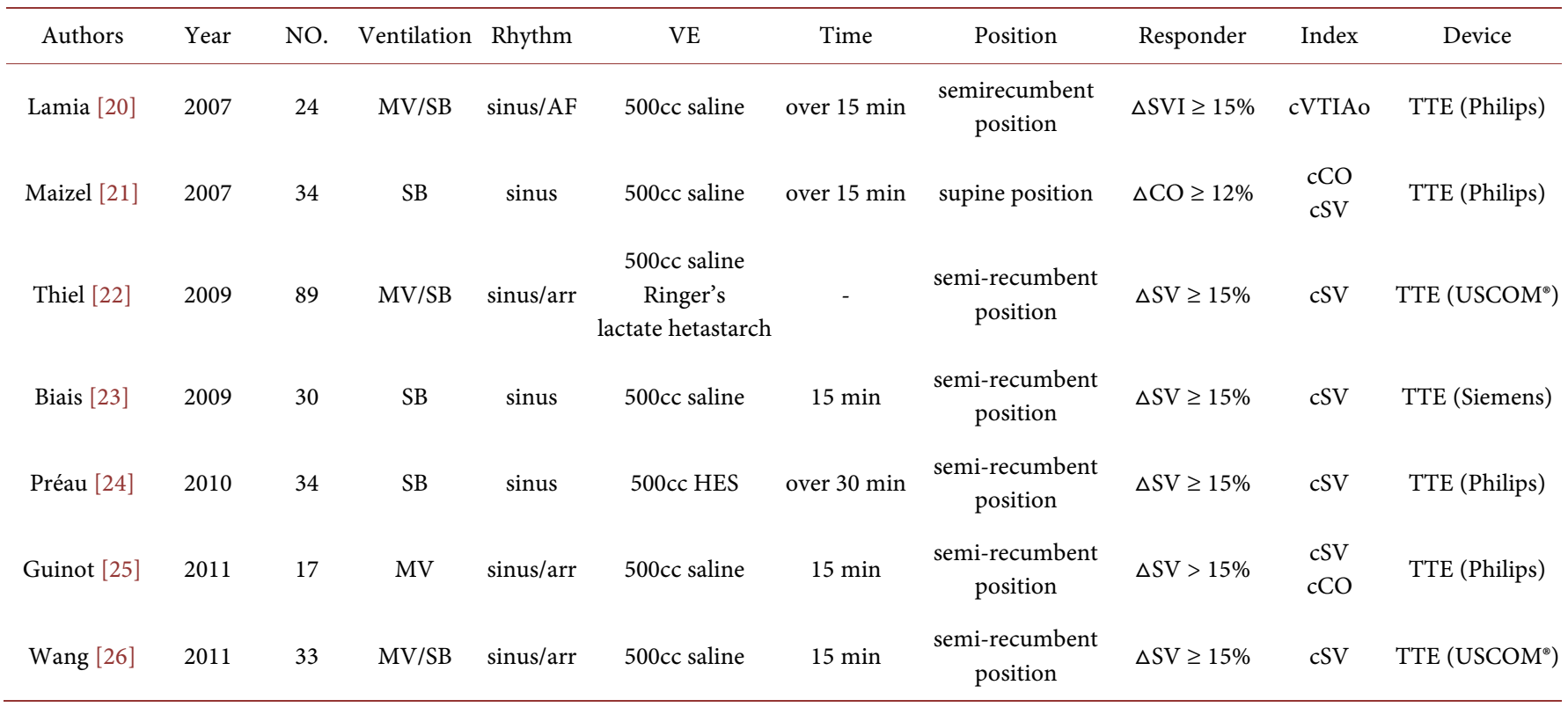

$\mathrm{MV}$, mechanical ventilation, arr, arrhythmia, AF, atrial fibrillation, VE, volume expansion, min, minutes, $\Delta$, variation; $\mathrm{c}$ PLR induced changes in, CO, cardiac output, SV, stroke volume, VTIAo, aortic velocity-time integral, SVI, stroke volume index, TTE, transthoracic echocardiography, USCOM, transthoracic Doppler ultrasonography. 
Table 2. Main results of studies included in this meta-analysis on TTE in predicting fluid responsiveness by PLR.

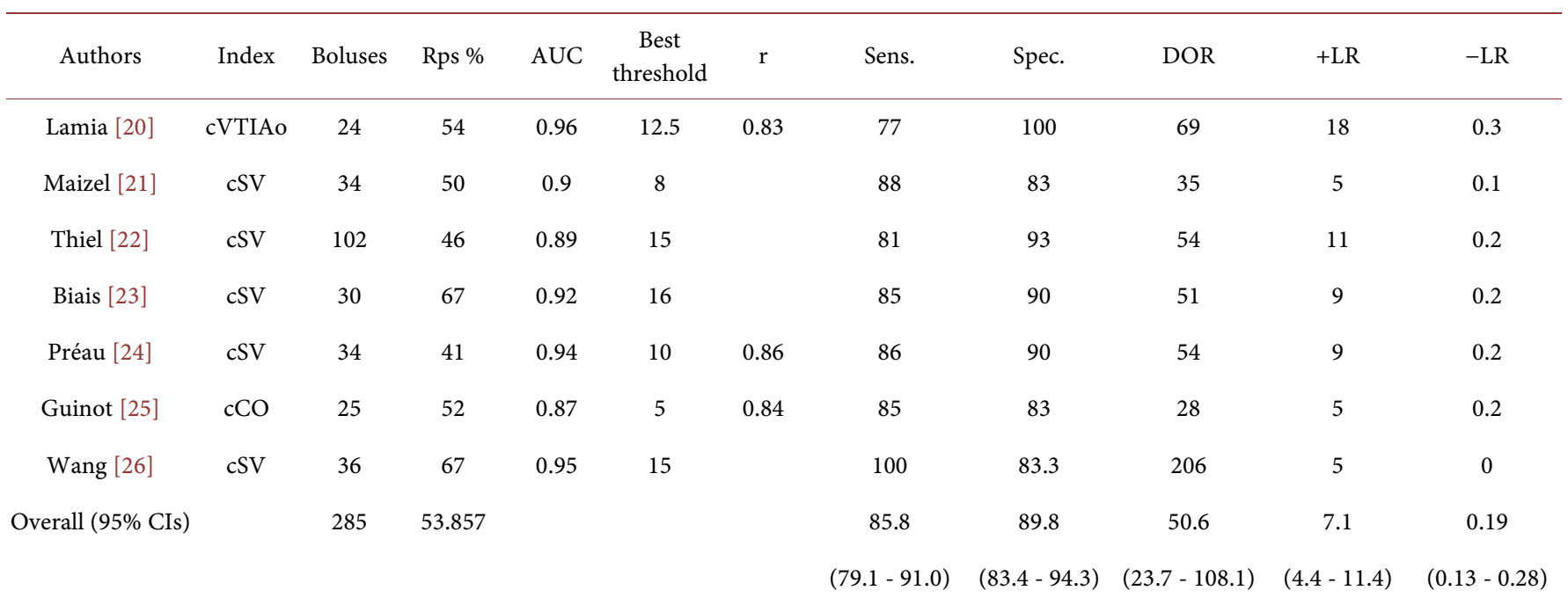

AUC, area under the receiver operating characteristics curve, c PLR induced changes in, Rps, responders, 95\% CIs, 95\% confidence intervals, Sens, sensitivity, Spec, specificity, DOR, diagnostic odds ratio, +LR, positive likelihood ratio, -LR, negative likelihood ratio, SV, stroke volume, CO, cardiac output, VTIAo, aortic velocity-time integral.

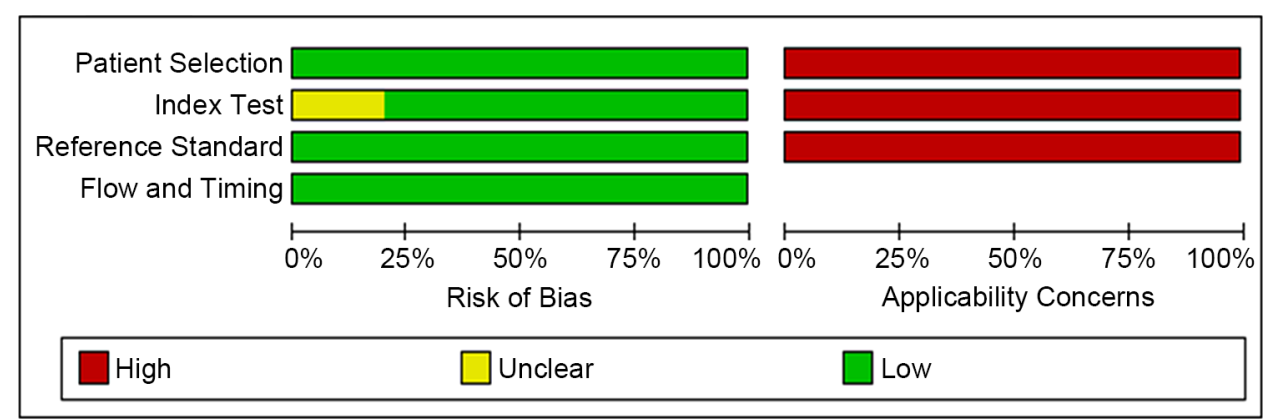

Figure 1. QUADAS-2 results of included studies on TTE in predicting fluid responsiveness by PLR (software RevMan 5.2).

\subsection{Diagnostic Accuracy}

Forest plots of the pooled sensitivity and specificity are shown in Figure 2.

The results $\mathrm{I} 2=0.0 \%(<50 \%)$ and $\mathrm{p}=0.972(>0.05)$ showed that heterogeneity was not significant among the trials. The sensitivity ranged from $77 \%-100 \%$ (pooled sensitivity $86 \%$, 95\% CI: 79\% - 91\%), while specificity ranged from $82 \%-100 \%$ (pooled specificity $90 \%$, 95\% CI: $83 \%$ - 94\%). The +LR was 7.07 (95\% CI: $4.39-11.38)$, -LR was 0.19 (95\% CI: 0.13 - 0.28), and DOR was 50.62 (95\% CI: 23.70 - 108.12). Chi-square values for sensitivity, specificity, $+\mathrm{LR},-\mathrm{LR}$, and DOR were $9.06(\mathrm{P}=0.17), 4.74(\mathrm{P}=$ 0.578), 2.53 ( $\mathrm{P}=0.865), 3.14(\mathrm{P}=0.792)$, and 1.29 ( $\mathrm{P}=0.972)$, respectively. These also indicated heterogeneity was not significant across studies regarding sensitivity, specificity, $+\mathrm{LR},-\mathrm{LR}$, and DOR.

As shown in Figure 3, the sROC curve showing sensitivity versus 1-specificity from individual studies is not positioned near the desirable upper left corner. The maximum joint sensitivity and specificity was 0.88 , with AUC of 0.94 . 


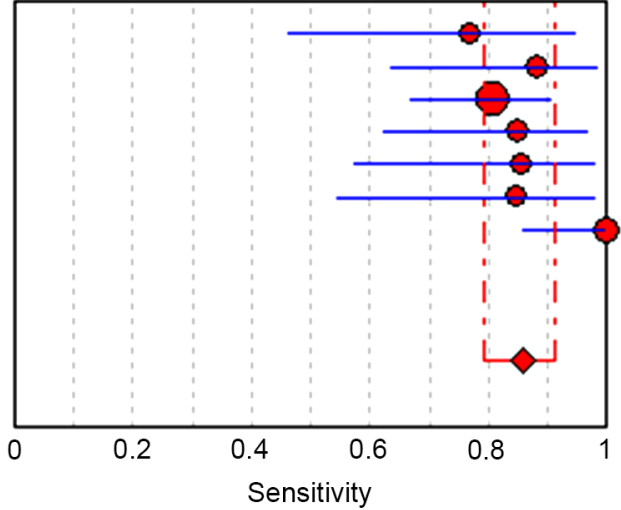

Lamia [1]

Maizel [2]

Thiel [3]

Biais [4]

Préau [5]

Guinot [6]

Wang [7]

Pooled Sensitivity $=0.86(0.79$ to 0.91$)$

Chi-square $=9.06 ; \mathrm{df}=6(p=0.1703)$

Inconsistency (l-square) $=33.8 \%$

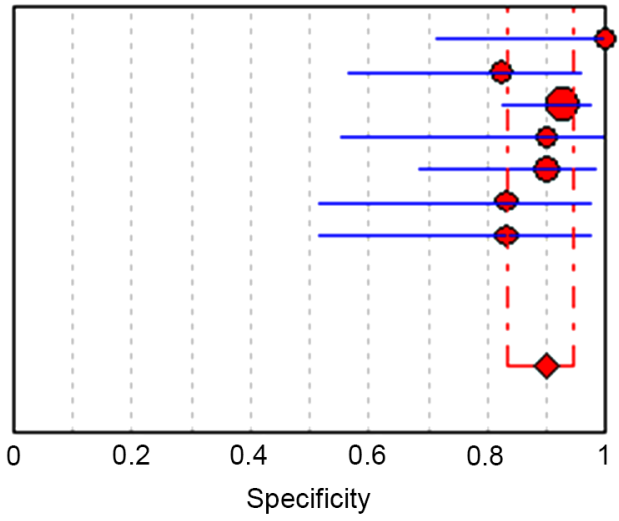

Lamia [1]

Maizel [2]

Thiel [3]

Biais [4]

Préau [5]

Guinot [6]

Wang [7]

Specificity $(95 \% \mathrm{CI})$

$1.00(0.72-1.00)$

$0.82(0.57-0.96)$

$0.93(0.82-0.98)$

$0.90(0.55-1.00)$

$0.90(0.68-0.99)$

$0.83(0.52-0.98)$

$0.83(0.52-0.98)$

Pooled Specificity $=0.90(0.83$ to 0.94$)$

Chi-square $=4.74 ; \mathrm{df}=6(p=0.5778)$

Inconsistency (I-square) $=0.0 \%$

Figure 2. Forest Plots of Pooled Sensitivity and specificity of the included studieson TTE in predicting fluid respon-siveness by PLR.

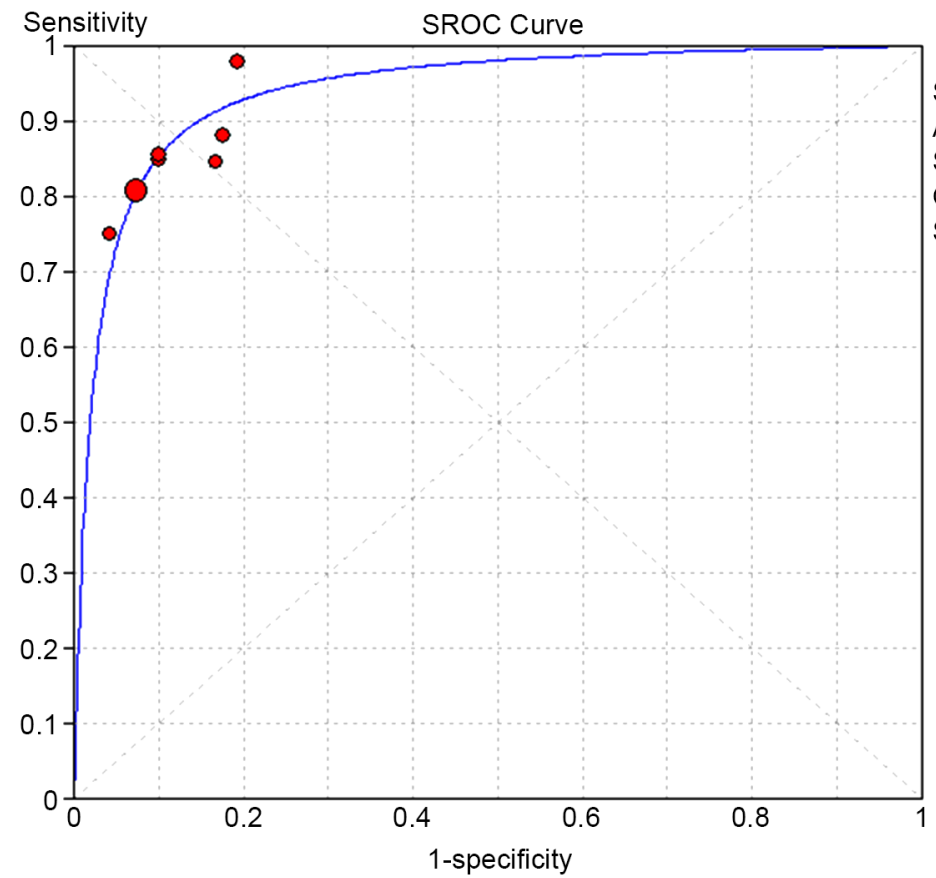

Symmetric SROC

$A \cup C=0.9412$

$\mathrm{SE}(\mathrm{AUC})=0.0174$

$Q^{*}=0.8790$

$\operatorname{SE}\left(Q^{*}\right)=0.0222$

Figure 3. Summary Receiver Operating Characteristics Curve for the ability of TTE in predicting fluid responsiveness by PLR. 
The Egger test and Begg test showed that the potential publication bias was significant $(\mathrm{P}<0.05)$, which indicated a potential for publication bias. Due to the limited number of included studies in the meta-analysis, funnel plots were not assessed.

\section{Discussion}

The results of the present meta-analysis demonstrate that the pooled sensitivity and specificity of TTE are $86 \%(79 \%-91 \%)$ and $90 \%(83 \%-94 \%)$, respectively. The sROC curve shows an optimum joint sensitivity and specificity of 0.88 , with AUC of 0.94 , which indicates that TTE is good tool to be used to predict fluid responsiveness. The result of DOR is 50.62 (95\% CI: 23.70 - 108.12), which indicates using non-invasive techniques have better discriminatory test performance with higher DOR values [8]; the results of +LR and -LR are 7.07 (95\% CI: 4.39 - 11.38) and 0.19 (95\% CI: 0.13 - 0.28). +LR above 5 and -LR below 0.2 have been noted as providing strong diagnostic evidence [27].

Passive leg raising (PLR) is a reversible maneuver that mimics rapid VE by shifting venous blood from the lower limbs to the intrathoracic compartment and introduces a reversible increase in preload of the right [28] and left ventricle [29]. TTE is a safe and convenient hemodynamic tool, which enable clinicians make fast assessment of patients' volume statue at the bedside, especially in patients with spontaneous breathing. In such patients, volume responsiveness is difficult to predict [30] [31]. TTE techniques appear useful in patients with spontaneous respiratory effort and those with arrhythmias: this is in contrast to many of the techniques that involve invasive monitoring which have been shown to be inaccurate in these situations [32]. But the operation of TTE really needs qualified clinicians. A good clinician can obtain the information from the TTE screen accurately.

A recent study by Mandeville et al. [33] concludes that TTE accurately predict fluid responsiveness in critically ill patients with discriminative power not affected by the technique selected. But the predictive value of TTE has not been evaluated yet. In this meta-analysis, it has been suggested that TTE could accurately predict fluid responsiveness by passive leg raising in the critically ill patients.

This meta-analysis has certain limitations. First, thoracic or abdominal wounds may sometimes make views impossible to achieve and obesity or rib prominence can also make TTE acoustic windows difficult to obtain. Second, TTE requires qualified clinician-echocardiographers through a defined training process, who can obtain information from the screen of TTE accurately and answer to the daily clinical conundrum of fluid responsiveness. Third, small size of the studies is included in this study with only a single study included 89 patients [20]. However, Zhang et al confirmed that small trials are more likely to report larger beneficial effects than large trials in critical care medicine, and Caution should be practiced in the interpretation of meta-analyses involving small trials [34]. Finally, the pooling of diagnostic accuracy data inevitably contribute to sources of bias [29], which are revealed in the significant amount of statistical heterogeneity across studies. As positive results of studies are more likely to be published, 
publication bias may be introduced by inflation of diagnostic accuracy estimates.

TTE is a repeatable and reliable noninvasive tool to predict fluid responsiveness in the critically ill during PLR with good test performance. This meta-analysis gives evidence to bring up well-trained clinician-echocardiographers to assess patients' volume statue via TTE to benefit daily work in ICUs.

\section{Financial Support and Sponsorship}

This work was supported by the grants from the Fundamental Research Funds for the Central Universities (15ykpy14) and Sun Yat-sen University Clinical Research 5010 Program (2007015).

\section{Conflicts of Interest}

There are no conflicts of interest.

\section{References}

[1] Schuller, D. and Schuster, D.P. (2006) Fluid-Management Strategies in Acute Lung Injury. The New England Journal of Medicine, 355, 1175

[2] Wiedemann, H.P., Wheeler, A.P., Bernard, G.R., Thompson, B.T., Hayden, D. and de Boisblanc, B. (2006) Comparison of Two Fluid-Management Strategies in Acute Lung Injury. The New England Journal of Medicine, 354, 2564-2575.

[3] Marik, P.E., Monnet, X. and Teboul, J.L. (2011) Hemodynamic Parameters to Guide Fluid Therapy. Annals of Intensive Care, 1, 1. http://dx.doi.org/10.1186/2110-5820-1-1

[4] Kircher, B.J., Himelman, R.B. and Schiller, N.B. (1990) Noninvasive Estimation of Right Atrial Pressure from the Inspiratory Collapse of the Inferior Vena Cava. The American Journal of Cardiology, 66, 493-496.

[5] Michard, F. and Teboul, J.L. (2002) Predicting Fluid Responsiveness in ICU Patients: Acritical Analysis of the Evidence. Chest, 121, 2000-2008.

http://dx.doi.org/10.1378/chest.121.6.2000

[6] Osman, D., Ridel, C., Ray, P., Monnet, X., Anguel, N., Richard, C., et al. (2007) Cardiacfilling Pressures Are Not Appropriate to Predict Hemodynamic Response to Volume Challenge. Critical Care Medicine, 35, 64-68.

[7] Slama, M., Masson, H., Teboul, J.L., Arnout, M.L., Susic, D., Frohlich, E., et al. (2002) Respiratory Variations of Aortic VTI: A New Index of Hypovolemia and Fluidresponsiveness. American Journal of Physiology-Heart and Circulatory Physiology, 283, H1729-H1733. http://dx.doi.org/10.1152/ajpheart.00308.2002

[8] Feissel, M., Michard, F., Mangin, I., Ruyer, O., Faller, J.P. and Teboul, J.L. (2001) Respiratorychanges in Aortic Blood Velocity as an Indicator of Fluid Responsiveness Inventilated Patients with Septic Shock. Chest, 119, 867-873. http://dx.doi.org/10.1378/chest.119.3.867

[9] Monnet, X., Bleibtreu, A., Ferré, A., Dres, M., Gharbi, R., Richard, C., et al. (2012) Passiveleg-Raising and End-Expiratory Occlusion Tests Perform Better than Pulsepressure Variation in Patients with Low Respiratory System Compliance. Critical Care Medicine, 40, 152-157. http://dx.doi.org/10.1097/CCM.0b013e31822f08d7

[10] Pronovost, P., Needham, D., Berenholtz, S., Sinopoli, D., Chu, H.T., et al. (2006) An Intervention to Decrease Catheter-Related Bloodstream Infections in the ICU. The New England Journal of Medicine, 355, 2725-2732. http://dx.doi.org/10.1056/NEJMoa061115 
[11] Rutlen, D.L., Wackers, F.J. and Zaret, B.L. (1981) Radionuclide Assessment of Peripheral Intravascular Capacity: A Technique to Measure Intravascular Volume Changes in the Capacitance Circulation in Man. Circulation, 64, 146-152.

http://dx.doi.org/10.1161/01.CIR.64.1.146

[12] Lafanechere, A., Pene, F., Goulenok, C., Delahaye, A., Mallet, V., et al. (2006) Changes in Aortic Blood Flow Induced by Passive Leg Raising Predict Fluid Responsiveness in Critically Ill Patients. Critical Care, 10, R132. http://dx.doi.org/10.1186/cc5044

[13] Monnet, X., Rienzo, M., Osman, D., Anguel, N., Richard, C., et al. (2006) Passive Leg Raising Predicts Fluid Responsiveness in the Critically Ill. Critical Care Medicine, 34, 1402-1407. http://dx.doi.org/10.1097/01.CCM.0000215453.11735.06

[14] Joseph, M.X., Disney, P.J., Da Costa, R. and Hutchison, S.J. (2004) Transthoracic Echocardiography to Identify or Exclude Cardiac Cause of Shock. Chest, 126, 1592-1597. http://dx.doi.org/10.1378/chest.126.5.1592

[15] Bossuyt, P.M., Reitsma, J.B., Bruns, D.E., Gatsonis, C.A., Glasziou, P.P., et al. (2003) Towards Complete and Accurate Reporting of Studies of Diagnostic Accuracy: The STARD Initiative. Clinical Chemistry and Laboratory Medicine, 41, 68-73. http://dx.doi.org/10.1309/8exccm6yr1thubaf

[16] Whiting, P.F., Rutjes, A.W.S., Westwood, M.E., Mallett, S., Deeks, J.J., et al. (2011) QUADAS-2: A Revised Tool for the Quality Assessment of Diagnostic Accuracy Studies. Annals of Internal Medicine, 155, 529-536. http://dx.doi.org/10.7326/0003-4819-155-8-201110180-00009

[17] Devillé, W.L., Buntinx, F., Bouter, L.M., Montori, V.M., de Vet, H.C., van der Windt, D.A.W.M. and Bezemer, P.D. (2002) Conducting Systematic Reviews of Diagnostic Studies: Didactic Guidelines. BMC Medical Research Methodology, 2, 9. http://dx.doi.org/10.1186/1471-2288-2-9

[18] Moses, L.E., Shapiro, D. and Littenberg, B. (1993) Combining Independent Studies of a Diagnostic Test into a Summary ROC Curve: Data-Analytic Approaches and Some Additional Considerations. Statistics in Medicine, 12, 1293-1316. http://dx.doi.org/10.1002/sim.4780121403

[19] Egger, M., Smith, G.D., Schneider, M. and Minder, C. (1997) Bias in Meta-Analysis Detected by a Simple, Graphical Test. BMJ, 315, 629-634.

http://dx.doi.org/10.1136/bmj.315.7109.629

[20] Begg, C.B. and Mazumdar, M. (1994) Operating Characteristics of a Rank Correlation Test for Publication Bias. Biometrics, 50, 1088-1101. http://dx.doi.org/10.2307/2533446

[21] Lamia, B., Ochagavia, A., Monnet, X., Chemla, D., Richard, C. and Teboul, J.-L. (2007) Echocardiographic Prediction of Volume Responsiveness in Critically Ill Patients with Spontaneously Breathing Activity. Intensive Care Medicine, 33, 1125-1132. http://dx.doi.org/10.1007/s00134-007-0646-7

[22] Maizel, J., Airapetian, N., Lorne, E., Tribouilloy, C., Massy, Z. and Slama, M. (2007) Diagnosis of Central Hypovolemia by Using Passive Leg Raising. Intensive Care Medicine, 33, 1133-1138. http://dx.doi.org/10.1007/s00134-007-0642-y

[23] Thiel, S., Kollef, M. and Isakow, W. (2009) Non-Invasive Stroke Volume Measurement and Passive Leg Raising Predict Volume Responsiveness in Medical ICU Patients: An Observational Cohort Study. Critical Care, 13, R111. http://dx.doi.org/10.1186/cc7955

[24] Biais, M., Vidil, L., Sarrabay, P., Cottenceau, V., Revel, P. and Sztark, F. (2009) Changes in Stroke Volume Induced by Passive Leg Raising in Spontaneously Breathing Patients: Com-

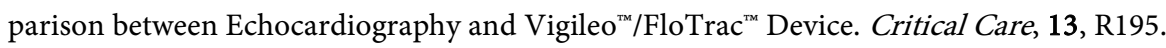


http://dx.doi.org/10.1186/cc8195

[25] Préau, S., Saulnier, F., Dewavrin, F., Durocher, A. and Chagnon, J.L. (2010) Passive Leg Raising Is Predictive of Fluid Responsiveness in Spontaneously Breathing Patients with Severe Sepsis or Acute Pancreatitis. Critical Care Medicine, 38, 819-825.

http://dx.doi.org/10.1097/CCM.0b013e3181c8fe7a

[26] Guinot, P.G., Zogheib, E., Detave, M., Moubarak, M., Hubert, V., et al. (2011) Passive Leg Raising Can Predict Fluid Responsiveness in Patients Placed on Venovenous Extracorporeal Membrane Oxygenation. Critical Care, 15, R216. http://dx.doi.org/10.1186/cc10451

[27] Wang, H.L., Liu, H.T. and Yu, K.L. (2011) Clinical Observation of Passive Leg Raising Combined with Non Invasive Cardiac Output Monitoring System in Predicting Volume Responsiveness. Chinese Critical Care Medicine, 23, 146-149.

[28] Thomas, M. and Shillingford, J. (1965) The Circulatory Response to a Standard Postural Change in Ischaemic Heart Disease. British Heart Journal, 27, 17-27. http://dx.doi.org/10.1136/hrt.27.1.17

[29] De Hert, S.G., Robert, D., Cromheecke, S., Michard, F., Nijs, J. and Rodrigus, I.E. (2006) Evaluation of Left Ventricular Function in Anesthetized Patients Using Femoral Artery $\mathrm{dP} / \mathrm{dt}_{\text {max. }}$. Journal of Cardiothoracic and Vascular Anesthesia, 20, 325-330. http://dx.doi.org/10.1053/j.jvca.2005.11.006

[30] Michard, F., Boussat, S., Chemla, D., Anguel, N., Mercat, A., et al. (2000) Relation between Respiratory Changes in Arterial Pulse Pressure and Fluid Responsiveness in Septic Patients with Acute Circulatory Failure. American Journal of Respiratory and Critical Care Medicine, 162, 134-138. http://dx.doi.org/10.1164/ajrccm.162.1.9903035

[31] Coudray, A., Romand, J.-A., Treggiari, M. and Bendjelid, K. (2005) Fluid Responsiveness in Spontaneously Breathing Patients: A Review of Indexes Used in Intensive Care. Critical Care Medicine, 33, 2757-2762. http://dx.doi.org/10.1097/01.CCM.0000189942.24113.65

[32] Michard, F. (2011) Stroke Volume Variation: From Applied Physiology to Improved Outcomes. Critical Care Medicine, 39, 402-403. http://dx.doi.org/10.1097/CCM.0b013e318205c0a6

[33] Mandeville, J.C. and Colebourn, C.L. (2012) Can Transthoracic Echocardiography Be Used to Predict Fluid Responsiveness in the Critically Ill Patient? A Systematic Review. Critical Care Research and Practice, 2012, Article ID: 513480. http://dx.doi.org/10.1155/2012/513480

[34] Zhang, Z., Xu, X. and Ni, H. (2013) Small Studies May Overestimate the Effect Sizes in Critical Care Meta-Analyses: A Meta-Epidemiological Study. Critical Care, 17, R2. http://dx.doi.org/10.1186/cc11919 
Submit or recommend next manuscript to SCIRP and we will provide best service for you:

Accepting pre-submission inquiries through Email, Facebook, LinkedIn, Twitter, etc. A wide selection of journals (inclusive of 9 subjects, more than 200 journals)

Providing 24-hour high-quality service

User-friendly online submission system

Fair and swift peer-review system

Efficient typesetting and proofreading procedure

Display of the result of downloads and visits, as well as the number of cited articles

Maximum dissemination of your research work

Submit your manuscript at: http://papersubmission.scirp.org/

Or contact ojem@scirp.org 